\title{
Diferentes Fontes de Proteína na Dieta Pré-Inicial de Frangos de Corte ${ }^{1}$
}

\author{
Flavio Alves Longo², José Fernando Machado Menten ${ }^{3}$, Adriana Ayres Pedroso ${ }^{2}$, Adriana Nogueira \\ Figueiredo ${ }^{2}$, Aline M. Calil Racanicci², Juliano Benedito Gaiotto ${ }^{2}$, José Otávio Berti Sorbara ${ }^{2}$
}

\begin{abstract}
RESUMO - Objetivou-se, com este estudo, determinar o valor de energia metabolizável aparente corrigida (EMAn) de ingredientes protéicos alternativos, para frangos de corte na fase pré-inicial, e avaliar os efeitos da utilização desses ingredientes na primeira semana de vida de frangos sobre o desempenho e o desenvolvimento do trato gastrintestinal (TGI). No ensaio de metabolismo, 288 aves (4 a 7 dias de idade) foram distribuídas em seis tratamentos (uma dieta-referência e cinco dietas com inclusão dos ingredientes-teste: isolado protéico de soja [IS], ovo em pó [OP], plasma sangüíneo [PS], farelo de glúten de milho [GM] e levedura seca [LS]) e quatro repetições de 12 aves. Na avaliação do desempenho e do TGI, 624 aves foram alojadas em baterias com seis tratamentos e quatro repetições de 26 aves. Os tratamentos consistiram em: 1 - dieta de milho e farelo de soja, 2 - dieta de milho e farelo de soja + IS, 3 - dieta de milho e farelo de soja + OP, 4 - dieta de milho e farelo de soja + PS, 5 - dieta de milho e farelo de soja + GM e 6 - dieta de milho e farelo de soja + LS As aves foram submetidas aos tratamentos de 1 a 7 dias de idade. Aos 1, 4 e 7 dias de idade, as aves foram abatidas para mensuração dos órgãos do TGI. A EMAn dos ingredientes foi de 2.110, 5.095, 3.831, 3.374 e 2.037 kcal/kg (na matéria natural) para IS, OP, PS, GM e LS, respectivamente. De maneira geral, o desempenho das aves de 1 a 7 dias de idade foi afetado pelos diferentes tratamentos, mas esse efeito não persistiu até os 21 dias. As diferentes fontes de proteína afetaram o desenvolvimento do TGI, mas esses efeitos não explicam o desempenho das aves.
\end{abstract}

Palavras-chave: desempenho, dieta pré-inicial, energia metabolizável, frangos de corte, proteína, trato gastrintestinal

\section{Different Sources of Protein in the Diet of Newly Hatched Chicks}

\begin{abstract}
The purpose of this study was to determine the N-corrected apparent metabolizable energy (EMAn) of alternative protein ingredients, for newly hatched chicks, and to evaluate the effects of the utilization of these ingredients in the first week broiler feed, on the performance and gastrointestinal tract (TGI) development. In the metabolism trial, 288 male chicks from 4 to 7 days were allotted to a completely randomized design with six treatments (a reference diet and five diets with inclusion of the test ingredients) and four replicates of 12 birds. The ingredients evaluated were: isolated soy protein (IS), dried whole eggs (OP), blood plasma (PS), corn gluten meal (GM) and dried sugar cane yeast (LS). To evaluate the performance and TGI, 624 birds were allocated in brooder batteries with six treatments and four replicates of 26 birds. The treatments were: 1 - corn and soybean meal diet, 2 - corn and soybean meal diet + IS, 3 - corn and soybean meal diet + OP, 4 - corn and soybean meal diet + PS, 5 - corn and soybean meal diet + GM and 6 - corn and soybean meal diet + LS. The birds received the treatments only from 1 to 7 days. Birds were sampled at 1,4 and 7 days of age in order to evaluate the TGI organs. The EMAn of the ingredients determined for chicks in the first week were 2,$110 ; 5,095 ; 3,831 ; 3,374$ and $2,037 \mathrm{kcal} / \mathrm{kg}$ (as-fed basis) for IS, OP, PS, GM and LS, respectively. In general, the performance of the birds from 1 to 7 days was affected by the different treatments, but this effect was not maintained up to 21 days. The different protein sources affected the TGI development, but these effects did not explain broiler performance.
\end{abstract}

Key Words: broilers, gastrointestinal tract, metabolizable energy, newly hatched chick diets, performance, protein

\section{Introdução}

Cerca de $20 \%$ da proteína residual do saco vitelino é representada pelas imunoglobulinas maternas, ficando evidente que o uso de proteínas do saco vitelino para fins nutricionais priva o pinto da proteção de anticorpos (Dibner, 1996). Com isso, os componentes residuais do saco vitelino não devem ser utilizados como fonte de energia e aminoácidos, uma vez que oferecem ao neonato macromoléculas com funções mais valiosas quando não metabolizadas (Maiorka, 2001).

Assim, com o objetivo de dar suporte ao seu crescimento, as aves necessitam adquirir rápida capacidade de absorver nutrientes externos (Jin et al., 1998). Iji et al. (2001) comentaram que a entrada de nutrientes do saco vitelino e da dieta exógena no intestino delgado serve como estímulo ao crescimento

\footnotetext{
1 Parte da Tese de doutorado do primeiro autor desenvolvida na ESALQ/USP. Projeto financiado pela FAPESP

${ }^{2}$ Estudantes de Pós-Graduação em Ciência Animal e Pastagens, ESALQ/USP, Piracicaba, SP.

3 Professor do Depto. de Zootecnia, ESALQ/USP, Piracicaba, SP (jfmmente@esalq.usp.br).
} 
e desenvolvimento do trato gastrintestinal (TGI) e, conseqüentemente, das funções de digestão e absorção.

A capacidade de digestão e absorção de proteínas sofre adaptações marcantes no período pós-eclosão, sendo que as pesquisas indicam que esses processos são influenciados pelo nível de alimentação e a composição da dieta (Corring, 1980). Durante esse período de desenvolvimento e amadurecimento do TGI, o aproveitamento de nutrientes, em geral, pode ser reduzido, principalmente durante os primeiros 7 a 10 dias pós-eclosão (Uni et al., 1995). Essa deficiência no aproveitamento dos nutrientes pelas aves na fase pré-inicial pode acarretar decréscimo dos valores de energia metabolizável (EM) das dietas.

O farelo de soja é a principal fonte protéica para frangos de corte, entretanto a presença de fatores antinutricionais, como os oligossacarídeos rafinose e estaquiose (Parsons et al., 2000), associados à imaturidade do trato digestivo (Iji et al., 2001), reduz ainda mais a digestibilidade e disponibilidade de energia deste ingrediente na fase pré-inicial. Tanto a EM quanto a digestibilidade dos nutrientes de dietas milhofarelo de soja para pintos aumentam de 0 a 21 dias de idade; essa diferença foi atribuída principalmente a mudanças no aproveitamento do farelo de soja (Batal \& Parsons, 2003).

Algumas fontes protéicas, como isolado protéico de soja, ovo em pó, plasma sangüíneo, glúten de milho e levedura seca, em função de suas características, poderiam ser utilizadas na fase pré-inicial, em busca de maior digestibilidade da dieta, bem como de propriedades nutricionais que, de certa forma, podem contribuir para o desenvolvimento neonatal da ave. Entre as características principais desses ingredientes podemos citar ausência de fatores antinutricionais e de carboidratos solúveis, principalmente os oligossacarídeos, do isolado protéico de soja (Goldflus, 2001; Batal \& Parsons, 2003).

O ovo em pó - considerado uma fonte de proteína animal de excelente qualidade - apresenta altos níveis de energia e aminoácidos essenciais, além de alto teor de imunoglobulinas (Junqueira et al., 2001; Figueiredo, 2002). No caso do plasma sangüíneo, trata-se de ingrediente com alta concentração de proteína animal e altos níveis de imunoglobulinas (Dudley-Cash, 2002).

O glúten de milho é resultado do processamento do milho, concentrando o teor protéico em torno de $60 \%$, ao passo que a levedura seca é obtida da sangria do leite de levedura no processo de fermentação etanólica, após termólise e secagem em condições definidas, contendo cerca de $33 \%$ de proteína bruta (Butolo, 2002). Poucos estudos foram conduzidos para avaliar estes ingrediente na fase préinicial quanto à sua contribuição em energia metabolizável para as aves, bem como seus efeitos sobre o desempenho.

Neste trabalho, objetivou-se determinar o valor de energia metabolizável de alguns ingredientes protéicos alternativos no período de 1 a 7 dias de idade e avaliar a utilização destes ingredientes, como fonte de proteína em dietas pré-iniciais, sobre o desenvolvimento do trato gastrintestinal e desempenho das aves.

\section{Material e Métodos}

Dois experimentos foram realizados com pintos de corte em sala climatizada do Laboratório de Nutrição e Crescimento Animal do Departamento de Zootecnia da ESALQ/USP, Piracicaba, sendo avaliados cinco ingredientes alternativos como fontes de proteína: o isolado protéico de soja $^{1}$ (IS), ovo em pó $^{2}(\mathrm{OP})$, plasma sangüíneo ${ }^{3}$ (PS), farelo de glúten de milho $-60 \%{ }^{4}(\mathrm{GM})$ e a levedura seca ${ }^{5}(\mathrm{LS})$.

\section{Experimento 1}

Foi realizado um ensaio de metabolismo utilizando-se 288 pintos de corte machos (marca comercial AgRoss) de 1 a 7 dias de idade, distribuídos em delineamento inteiramente casualizado com seis tratamentos e quatro repetições de 12 aves cada, alojados em baterias com aquecimento automático; sob o piso de arame havia bandejas revestidas com plástico, adequadas para coleta de excretas.

\footnotetext{
${ }^{1}$ Ardex ${ }^{\circledR}$ AF 066-960 (ADM Company).

2 Ovo Desidratado por "Spray-dried" (Sohovos Industrial Ltda).

3 AP-920 (APC - American Protein Corporation).

4 Protenose ${ }^{\circledR}$ (Corn Products Brasil).

5 Levedura seca de cana (Usina São Martinho).
}

R. Bras. Zootec., v.34, n.1, p.112-122, 2005 
Os tratamentos consistiram de uma dieta-referência à base em milho e farelo de soja; quatro dietas com $80 \%$ de dieta-referência $+20 \%$ dos ingredientes-teste (OP, PS, GM e LS); e uma dieta com $90 \%$ de dieta-referência $+10 \%$ de IS. A dieta-referência foi formulada de acordo com os níveis nutricionais propostos por Rostagno et al. (2000) (Tabela 1).

O período de 1 a 3 dias de vida das aves foi considerado a fase de adaptação às instalações e dietas experimentais. No intervalo de 4 a 7 dias de idade, foi utilizado o método de coleta total de excretas, sendo registradas as quantidades de dieta ingerida e excreta produzida.

As excretas foram coletadas duas vezes ao dia, identificadas e mantidas congeladas, sendo posteriormente descongeladas e homogeneizadas. Após a retirada das amostras representativas para cada repetição, as mesmas foram pré-secas em estufa com circulação de ar a $55^{\circ} \mathrm{C}$ por 72 horas e preparadas para análises posteriores, segundo Silva (1990). As amostras dos ingredientes, das dietas e excretas foram submetidas a determinações da matéria seca, nitrogênio e energia bruta.

Os resultados obtidos nas análises para a dieta ingerida e excreta produzida foram utilizados para determinar os valores de energia metabolizável aparente corrigida para o balanço de nitrogênio (EMAn) das dietas experimentais, segundoproposto por Matterson et al. (1965). A partir dos valores de EMAn determinados para as dietas experimentais, foi possível calcular os valores de EMAn de cada ingrediente-teste:

$$
\text { EMAn ing. }=\frac{\text { EMAn ref. }+(\text { EMAn teste }- \text { EMAn ref. })}{(\% \text { substituição } / 100)}
$$

em que EMAn - energia metabolizável aparente corrigida pelo balanço de nitrogênio calculada $(\mathrm{kcal} / \mathrm{kg})$; ing. - ingrediente testado; ref. - dietareferência; teste - dieta basal + ingrediente-teste; \% substituição - nível de substituição da dieta basal pelo ingrediente-teste.

Considerando-se os valores de energia bruta (EB) e a EMAn dos ingredientes, foram calculados os coeficientes de metabolizabilidade da energia bruta $(\mathrm{CMEB}=(\mathrm{EMAn} / \mathrm{EB}) \times 100)$.

\section{Experimento 2}

Foram utilizados 624 pintos de corte machos de um dia de idade (marca comercial AgRoss) provenientes de matrizes com 62 semanas de idade, alojados em
Tabela 1 - Composição percentual e valores nutricionais das dietas experimentais nas fases pré-inicial (Experimento 1) e inicial (Experimento 2)

Table 1 - Percentage composition and nutritional values of experimental diets on newly hatched (Trial 1) and

\begin{tabular}{|c|c|c|}
\hline $\begin{array}{l}\text { Ingredientes } \\
\text { Ingredients }\end{array}$ & $\begin{array}{c}\text { Pré-inicial } \\
\text { (experimento 1) } \\
\text { Newly hatched } \\
\text { (Trial 1) }\end{array}$ & $\begin{array}{cc} & \text { Inicial } \\
& \text { (experimento 2) } \\
& \text { Starter } \\
& (\text { Trial 2) } \\
(\%) & \end{array}$ \\
\hline $\begin{array}{l}\text { Milho } \\
\text { Ccorn }\end{array}$ & 57,30 & 62,60 \\
\hline $\begin{array}{l}\text { Farelo de soja } \\
\text { Soybean meal }\end{array}$ & 36,75 & 32,50 \\
\hline $\begin{array}{l}\text { Fosfato bicálcico } \\
\text { Dicalcium phosphate }\end{array}$ & 1,89 & 1,76 \\
\hline $\begin{array}{l}\text { Calcário calcítico } \\
\text { Limestone }\end{array}$ & 1,00 & 1,12 \\
\hline $\begin{array}{l}\text { Sal } \\
\text { Salt }\end{array}$ & 0,50 & 0,40 \\
\hline $\begin{array}{l}\text { DL-Metionina } \\
\text { DL-methionine }\end{array}$ & 0,21 & 0,17 \\
\hline $\begin{array}{l}\text { L-lisina. } \mathrm{HCl} \\
\text { L-lysine }\end{array}$ & 0,18 & 0,20 \\
\hline $\begin{array}{l}\text { Cloreto de colina }-60 \% \\
\text { Choline chloride }\end{array}$ & 0,05 & 0,05 \\
\hline $\begin{array}{l}\text { Óleo vegetal } \\
\text { Vegetableoil }\end{array}$ & 1,92 & 1,12 \\
\hline $\begin{array}{l}\text { Suplemento vitamínico } \\
\text { Vitamin mix }\end{array}$ & 0,10 & 0,08 \\
\hline $\begin{array}{l}\text { Suplemento mineral }{ }^{2} \\
\text { Mineral mix }\end{array}$ & 0,10 & 0,10 \\
\hline
\end{tabular}
starter phases (Trial 2)

\begin{tabular}{|c|c|c|}
\hline \multicolumn{3}{|l|}{$\begin{array}{l}\text { Composição calculada } \\
\text { Calculated composition }\end{array}$} \\
\hline $\mathrm{EM}(\mathrm{kcal} / \mathrm{kg})$ & 2.950 & 3.050 \\
\hline $\begin{array}{l}M E \\
\mathrm{~PB}(\%)\end{array}$ & 21,92 & 21,22 \\
\hline $\begin{array}{l}C P \\
\text { Metionina (\%) } \\
\text { Methionine }\end{array}$ & 0,54 & 0,49 \\
\hline $\begin{array}{l}\text { Metionina + cistina }(\%) \\
\text { Methionine + cystine }\end{array}$ & 0,93 & 0,85 \\
\hline $\begin{array}{l}\text { Lisina }(\%) \\
\text { Lysine }\end{array}$ & 1,31 & 1,26 \\
\hline $\begin{array}{l}\text { Arginina }(\%) \\
\text { Arginine }\end{array}$ & 1,45 & 1,36 \\
\hline $\begin{array}{l}\text { Treonina }(\%) \\
\text { Threonine }\end{array}$ & 0,84 & 0,82 \\
\hline $\begin{array}{l}\text { Triptofano }(\%) \\
\text { Tryptophan }\end{array}$ & 0,27 & 0,25 \\
\hline $\begin{array}{l}\text { Fósforo disponível (\%) } \\
\text { Available phosphorus }\end{array}$ & 0,47 & 0,45 \\
\hline $\begin{array}{l}\text { Cálcio }(\%) \\
\text { Calcium }\end{array}$ & 0,99 & 0,96 \\
\hline
\end{tabular}

${ }^{1}$ Quantidade por kg de ração nos experimentos 1 e 2 , respectivamente (supplying per $\mathrm{kg}$ of feed in trials 1 and 2, respectively): vit. A, 10.000 e 8.000 UI; vit. $D_{3}, 2.000$ e 1.600 UI; vit. E, 12,5 e $10 \mathrm{mg}$; vit. $\mathrm{K}_{3}, 2,5$ e $2 \mathrm{mg}$; vit. $\mathrm{B}_{1}, 2,4$ e $1,92 \mathrm{mg}$; vit. $\mathrm{B}_{2}, 6,0$ e $4,8 \mathrm{mg}$; vit. $\mathrm{B}_{6}, 3,2$ e 2,56 mg; vit. $\mathrm{B}_{12}, 12$ e 9,6 $\mu$ g; ácido fólico (folic acid), 1,0 e 0,8 mg; pantotenato de $\mathrm{Ca}$ (calcium pantotenate), 12,5 e $10 \mathrm{mg}$; niacina (niacin), 30 e $24 \mathrm{mg}$; selênio (selenium), 0,2 e $0,16 \mathrm{mg}$; BHT, 15 e $12 \mathrm{mg}$.

${ }^{2}$ Quantidade por kg de ração (supplying per kg of feed): manganês (manganese), $65 \mathrm{mg}$; cobre (copper), $12 \mathrm{mg}$; zinco (zinc), $50 \mathrm{mg}$; ferro (iron), $40 \mathrm{mg}$; iodo (iodine), $1 \mathrm{mg}$. 
baterias com aquecimento automático e distribuídos em delineamento inteiramente casualizado com seis tratamentos e quatro repetições de 26 aves.

Os tratamentos foram aplicados de 1 a 7 dias, sendo que, no período subseqüente (8 a 21 dias), as aves receberam uma dieta basal padrão (Tabela 1). Os tratamentos consistiram em: 1 - dieta de milho e farelo de soja (testemunha), 2 - dieta de milho e farelo de soja + IS, 3 - dieta de milho e farelo de soja + OP, 4 - dieta de milho e farelo de soja + PS, 5 - dieta de milho e farelo de soja + GM, 6 - dieta de milho e farelo de soja + LS.

As dietas experimentais fornecidas nos experimentos para avaliação dos ingredientes como fonte de proteínas na fase pré-inicial (Tabela 2) foram formuladas para atender às exigências nutricionais propostas por Rostagno et al. (2000), sendo apenas ajustados os valores de EM para a fase de 2.950 para $2.800 \mathrm{kcal} / \mathrm{kg}$. Esse ajuste foi considerado aplicando-se os valores de EMAn determinados para o milho e farelo de soja na fase pré-inicial, conforme proposto por Menten et al. (2002).

$\mathrm{Na}$ formulação das dietas contendo os ingredientes protéicos, além do valor de EMAn determinado no Experimento 1, foi considerado o teor de proteína bruta analisado do ingrediente, de forma que o mesmo participou na dieta contribuindo com $20 \%$ do valor de proteína bruta total.

Nos períodos de 1 a 7 e 8 a 21 dias, foram controlados o consumo de ração, ganho de peso, conversão alimentar e viabilidade criatória. No primeiro, sétimo e $21^{\circ}$ dia de idade, as aves foram pesadas individualmente para o cálculo de uniformidade da parcela, considerando como uniformidade o coeficiente de variação do peso individual das aves da parcela.

Antes do alojamento, quatro aves foram retiradas para avaliação inicial dos órgãos (dia zero). Aos um (24 horas após fornecimento das dietas experimentais), 4 e 7 dias de idade foram retiradas, aleatoriamente, duas aves por parcela, as quais foram abatidas por deslocamento cervical e os órgãos do TGI retirados para mensurações. Foram determinados o peso relativo (\% do peso vivo) do saco vitelino residual, proventrículo, moela, pâncreas, fígado e o peso vazio relativo (\% do peso vivo), comprimento $(\mathrm{cm})$ e densidade $(\mathrm{mg} / \mathrm{cm})$ do intestino delgado.

Os coeficientes de metabolizabilidade dos ingredientes avaliados, os resultados de desempenho e desenvolvimento dos órgãos do TGI foram submetidos à análise de variância pelo PROC GLM (General Linear Models) do programa Statistical Analysis System (SAS, 1996). As médias obtidas foram comparadas pelo teste de Tukey a 5 e $10 \%$ de probabilidade.

\section{Resultados e Discussão}

\section{Experimento 1}

Os valores da composição em matéria seca (MS), energia bruta (EB), proteína bruta $(\mathrm{PB})$ e extrato etéreo (EE) dos ingredientes avaliados no ensaio são apresentados na Tabela 3 e estão de acordo com os valores encontrados em tabelas nutricionais.

Na Tabela 4, são apresentados os valores calculados de EMAn e o coeficiente de metabolizabilidade da energia bruta (CMEB) dos ingredientes avaliados no ensaio de metabolismo, além de valores de EMA descritos na literatura. Verifica-se que os valores de EMAn dos ingredientes, para pintos de 1 a 7 dias de idade, foram diferentes dos apresentados na literatura (NRC, 1994; Rostagno et al., 2000; D'Agostini et al., 2001; Harmon et al., 2001). Essa diferença já era esperada, e se justifica, pois a literatura se refere a ingredientes avaliados com aves em outras fases de criação.

Os ingredientes de origem animal (OP e PS) apresentaram valores de EMAn superiores, enquanto os de origem vegetal (IS, GM e LS), valores inferiores ou semelhantes aos encontrados na literatura.

Maior valor de CMEB também foi observado para as fontes protéicas de origem animal $(\mathrm{P}<0,05)$, de 86,26 e $80,99 \%$, para o OP e PS, respectivamente. Esses resultados podem estar evidenciando a maior facilidade de aproveitamento de ingredientes de origem animal, provavelmente em razão de o perfil dos nutrientes presentes ser mais semelhante ao de nutrientes encontrados no saco vitelino.

Além disso, deve-se considerar que a proteína do ovo é rica em imunoglobulinas, mais especificamente gamaglobulinas (Figueiredo, 2002), sendo que a principal fração protéica do saco vitelino residual é composta de imunoglobulinas maternas (Dibner, 1996). O plasma sangüíneo também é rico em imunoglobulinas e essa fração apresenta funções biológicas importantes, principalmente para leitões na fase de desmame (Campbell et al., 1998).

Os CMEB dos ingredientes de origem vegetal foram inferiores $(\mathrm{P}<0,05)$ em relação aos das fontes de proteína animal. Os menores valores observados de 44,54 e 49,97\% para o IS e LS, respectivamente, 
Tabela 2 - Composição percentual e valores nutricionais das dietas experimentais na fase pré-inicial para avaliação das fontes de proteínas (Experimento 2)

Table 2 - Percentage composition and nutritional values of experimental diets to evaluate protein sources for newly hatched chicks (Trial 2)

\begin{tabular}{|c|c|c|c|c|c|c|}
\hline $\begin{array}{l}\text { Ingredientes } \\
\text { Ingredients }\end{array}$ & $\begin{array}{c}\text { Testemunha } \\
\text { (TES) } \\
\text { Control }\end{array}$ & $\begin{array}{l}\text { Isol. prot. } \\
\text { soja (IS) } \\
\text { Isolated soy } \\
\text { protein }\end{array}$ & $\begin{array}{l}\text { Ovo em pó } \\
\text { (OP) } \\
\text { Dried } \\
\text { whole egg }\end{array}$ & $\begin{array}{c}\text { Plasma } \\
\text { sangüíneo (PS) } \\
\text { Blood } \\
\text { plasma }\end{array}$ & $\begin{array}{l}\text { Glúten de } \\
\text { milho }(\mathrm{GM}) \\
\text { Corn gluten } \\
\text { meal }\end{array}$ & $\begin{array}{l}\text { Levedura }(\mathrm{LS}) \\
\text { Dried sugar } \\
\text { cane yeast }\end{array}$ \\
\hline $\begin{array}{l}\text { Milho }{ }^{1} \\
\text { Corn }\end{array}$ & 61,19 & 67,29 & 57,68 & 64,91 & 63,27 & 54,10 \\
\hline $\begin{array}{l}\text { Farelo de soja } 1 \\
\text { Soybean meal }\end{array}$ & 33,57 & 23,06 & 25,38 & 23,74 & 23,19 & 25,89 \\
\hline $\begin{array}{l}\text { Ingrediente-teste } \\
\text { Test ingredient }\end{array}$ & - & 5,35 & 8,03 & 5,59 & 7,30 & 13,65 \\
\hline $\begin{array}{l}\text { Fosfato bicálcico } \\
\text { Dicalcium phosphate }\end{array}$ & 1,86 & 1,89 & 1,73 & 1,90 & 1,91 & 1,76 \\
\hline $\begin{array}{l}\text { Calcário calcítico } \\
\text { Limestone }\end{array}$ & 1,04 & 1,08 & 1,19 & 1,06 & 1,08 & 1,07 \\
\hline $\begin{array}{l}\text { Óleo vegetal } \\
\text { Vegetable oil }\end{array}$ & 1,29 & 0,26 & - & - & - & 2,60 \\
\hline $\begin{array}{l}\text { Sal } \\
\text { Salt }\end{array}$ & 0,40 & 0,40 & 0,40 & 0,40 & 0,40 & 0,40 \\
\hline $\begin{array}{l}\text { DL-Metionina } \\
\text { DL-methionine }\end{array}$ & 0,18 & 0,19 & 0,04 & 0,20 & 0,17 & 0,16 \\
\hline $\begin{array}{l}\text { L-lisina. } \mathrm{HCl} \\
\text { L-lysine }\end{array}$ & 0,22 & 0,23 & 0,10 & 0,07 & 0,46 & 0,09 \\
\hline $\begin{array}{l}\text { Cloreto de colina } 60 \% \\
\text { Choline chloride } 60 \%\end{array}$ & 0,05 & 0,05 & 0,05 & 0,05 & 0,05 & 0,05 \\
\hline $\begin{array}{l}\text { L-arginina } \\
\text { L-arginine }\end{array}$ & - & - & - & 0,02 & 0,15 & 0,03 \\
\hline $\begin{array}{l}\text { L-treonina } \\
\text { L-threonine }\end{array}$ & - & - & - & - & 0,04 & - \\
\hline $\begin{array}{l}\text { Supl. vitamínico }{ }^{2} \\
\text { Vitamin mix }\end{array}$ & 0,10 & 0,10 & 0,10 & 0,10 & 0,10 & 0,10 \\
\hline $\begin{array}{l}\text { Supl. mineral } \\
\text { Mineral mix }\end{array}$ & 0,10 & 0,10 & 0,10 & 0,10 & 0,10 & 0,10 \\
\hline $\begin{array}{l}\text { Inerte (Inert) } \\
\text { Composição calculada } \\
\text { Calculated composition }\end{array}$ & - & - & 5,20 & 1,85 & 1,79 & - \\
\hline$\overline{\mathrm{EM}}(\mathrm{kcal} / \mathrm{kg})(M E)$ & 2.800 & 2.800 & 2.800 & 2.800 & 2.800 & 2.800 \\
\hline $\mathrm{PB}(\%)(C P)$ & 21,92 & 21,92 & 21,92 & 21,92 & 21,92 & 21,92 \\
\hline $\begin{array}{l}\text { Metionina }(\%) \\
\text { Methionine }\end{array}$ & 0,51 & 0,51 & 0,51 & 0,51 & 0,51 & 0,51 \\
\hline $\begin{array}{l}\text { Metionina + cistina }(\%) \\
\text { Methionine }+ \text { cystine }\end{array}$ & 0,87 & 0,87 & 0,91 & 0,94 & 0,85 & 0,82 \\
\hline $\begin{array}{l}\text { Lisina }(\%) \\
\text { Lysine }\end{array}$ & 1,31 & 1,31 & 1,31 & 1,31 & 1,31 & 1,31 \\
\hline $\begin{array}{l}\text { Arginina }(\%) \\
\text { Arginine }\end{array}$ & 1,39 & 1,43 & 1,37 & 1,33 & 1,33 & 1,33 \\
\hline $\begin{array}{l}\text { Treonina }(\%) \\
\text { Threonine }\end{array}$ & 0,83 & 0,83 & 0,88 & 0,96 & 0,82 & 0,93 \\
\hline $\begin{array}{l}\text { Triptofano }(\%) \\
\text { Tryptophan }\end{array}$ & 0,26 & 0,25 & 0,25 & 0,26 & 0,21 & 0,27 \\
\hline $\begin{array}{l}\text { P disponível (\%) } \\
\text { Available P }\end{array}$ & 0,47 & 0,47 & 0,47 & 0,47 & 0,47 & 0,47 \\
\hline $\begin{array}{l}\text { Cálcio }(\%) \\
\text { Calcium }\end{array}$ & 0,99 & 0,99 & 0,99 & 0,99 & 0,99 & 0,99 \\
\hline
\end{tabular}

\footnotetext{
${ }^{1}$ Composição em EM ajustado para a fase segundo proposto por Menten et al. (2002) (ME composition adjusted for the phase proposed by Menten et al. [2002]).

${ }^{2}$ Fornecido por kg de ração (supplying per kg of feed): vit. A, $10.000 \mathrm{UI}$; vit. D3, $2.000 \mathrm{UI}$; vit. E, $12,5 \mathrm{mg}$; vit. $\mathrm{K}_{3}$, 2,5 mg; vit. $\mathrm{B}_{1}$, 2,4 mg; vit. $\mathrm{B}_{2}, 6,0 \mathrm{mg}$; vit. $\mathrm{B}_{6}, 3,2 \mathrm{mg}$; vit. $\mathrm{B}_{12}, 0,012 \mathrm{mg}$; ácido fólico (folic acid), 1,0 mg; pantotenato de Ca (calcium pantotanate), $12,5 \mathrm{mg} ;$ niacina (niacin), $30 \mathrm{mg}$; selênio (selenium), 0,2 mg; BHT, $15 \mathrm{mg}$.

${ }^{3}$ Fornecido por $\mathrm{kg}$ de ração (supplying per $\mathrm{kg}$ of feed): manganês (manganese), $65 \mathrm{mg}$; cobre (copper), $12 \mathrm{mg}$; zinco (zinc), $50 \mathrm{mg}$; ferro (iron), $40 \mathrm{mg}$; iodo (iodine), $1 \mathrm{mg}$.
}

\section{R. Bras. Zootec., v.34, n.1, p.112-122, 2005}


são indicativos de que o processamento da soja, responsável pela retirada dos oligossacarídeos, não foi suficiente para melhorar a digestibilidade da energia do IS e que a LS não possui uma composição que favoreça o aproveitamento energético para pintos na primeira semana. Entre as fontes de origem vegetal, o GM apresentou melhor metabolizabilidade $(66,02 \%)$, resultado provável da presença residual de amido e gérmen provenientes do processamento do milho.

Essas diferenças encontradas entre valores de EMAn calculados no ensaio e da literatura, bem como no aproveitamento energético (CMEB) do ingrediente estão relacionadas principalmente à imaturidade do TGI, promovendo modificações na capacidade digestiva e absortiva da ave, evidenciando que as características metabólicas existentes em cada fase de desenvolvimento podem afetar o valor energético dos alimentos e, conseqüentemente, alterar o valor de energia metabolizável fornecido na dieta. Portanto, a determinação da EMAn desses ingredientes visa uma formulação mais precisa e adequada para a fase pré-inicial das aves, uma vez que, segundo Nir (1998), os valores de EMAn de alimentos encontrados em tabelas da literatura estão acima dos valores corretos para pintos na primeira semana.

\section{Experimento 2}

A fonte de proteína promoveu alterações significativas $(\mathrm{P}<0,05)$ no consumo de ração das aves de 1 a 7 dias de idade, sendo que a adição de LS resultou em maior consumo, não diferindo significativamente apenas do tratamento testemunha (TES). Em contrapartida, o tratamento com IS prejudicou o consumo de ração (Tabela 5).

Tabela 3 - Valores determinados de matéria seca (MS), energia bruta (EB), proteína bruta (PB) e extrato etéreo (EE) dos ingredientes

Table 3 - Determined values for dry matter (MS), gross energy $(E B)$, crude protein $(C P)$ and ether extract $(E E)$ of the ingredient

\begin{tabular}{lcccc}
\hline $\begin{array}{l}\text { Ingredientes } \\
\text { Ingredients }\end{array}$ & $\begin{array}{c}\mathrm{MS} \\
(\%)\end{array}$ & $\begin{array}{c}\mathrm{EB} \\
(\mathrm{kcal} / \mathrm{kg}) *\end{array}$ & $\begin{array}{c}\mathrm{PB} \\
(\%)^{*}\end{array}$ & $\begin{array}{c}\mathrm{EE} \\
(\%)^{*}\end{array}$ \\
\hline $\mathrm{IS}$ & 98,96 & 4738 & 81,86 & 0,47 \\
OP & 99,24 & 5907 & 54,62 & 14,00 \\
PS & 97,26 & 4730 & 78,44 & 0,48 \\
GM & 94,89 & 5111 & 60,07 & 0,95 \\
LS & 93,87 & 4077 & 32,12 & 0,01 \\
\hline
\end{tabular}

* Valores expressos na matéria natural (Values as fed basis).
Verifica-se uma relação entre o tratamento com IS, que prejudicou o consumo de ração pelas aves, com as características de menor textura e maior pulverulência da dieta. Para o tratamento com LS, cuja dieta continha como características maior textura e menor pulverulência, além de maior inclusão de óleo vegetal (Tabela 2), verificou-se maior consumo de ração pelas aves. Essa variação no consumo de ração confirma os relatos apresentados por Shelton et al. (2003), que justificaram a menor ingestão de dietas pré-iniciais contendo isolado protéico de soja pelas características observadas também no presente trabalho, afetando a aceitabilidade da mesma pelas aves. Os efeitos dessas características de textura e pulverulência dos ingredientes sobre o consumo de ração talvez não fossem observados no caso de rações processadas por peletização.

A alteração no consumo de ração associada à resposta de ganho de peso semelhante entre os tratamentos promoveu diferenças significativas $(\mathrm{P}<0,05)$ na conversão alimentar, sendo que as aves que receberam os tratamentos com IS e PS apresentaram uma melhora, enquanto que o tratamento com LS prejudicou a conversão alimentar das aves. As

Tabela 4 - Valores calculados e seus respectivos desviospadrão para a energia metabolizável aparente corrigida pelo balanço de nitrogênio (EMAn) e o coeficiente de metabolizabilidade da energia bruta (CMEB) dos ingredientes avaliados no ensaio experimental

Table 4 - Calculated values and respective standard deviations for $\mathrm{N}$-corrected apparent metabolizable energy (EMAn) and metabolizability coefficient of gross energy (CMEB) of the ingredients evaluated in the experimental trial

\begin{tabular}{lccc}
\hline $\begin{array}{l}\text { Ingredientes } \\
\text { Ingredients }\end{array}$ & $\begin{array}{c}\text { EMAn }^{1} \\
(\mathrm{kcal} / \mathrm{kg} \mathrm{MN})\end{array}$ & $\begin{array}{c}\text { CMEB } \\
(\%)\end{array}$ & $\begin{array}{c}\text { EMAn literatura }^{2} \\
(\mathrm{kcal} / \mathrm{kg} \mathrm{MN})\end{array}$ \\
\hline IS & $2.110 \pm 276$ & $44,54 \pm 5,82^{\mathrm{c}}$ & - \\
OP & $5.095 \pm 268$ & $86,26 \pm 4,54^{\mathrm{a}}$ & 4.700 \\
PS & $3.831 \pm 063$ & $80,99 \pm 1,32^{\mathrm{a}}$ & 3.474 \\
GM & $3.374 \pm 209$ & $66,02 \pm 4,08^{\mathrm{b}}$ & $3.720-3.775$ \\
LS & $2.037 \pm 199$ & $49,97 \pm 4,89^{\mathrm{c}}$ & $1.990-2.536$ \\
\hline
\end{tabular}

$a, b, c$. Médias seguidas de letras diferentes na mesma coluna diferem entre si pelo teste Tukey $(P<0,05)$ - coeficiente de variação $=6,70 \%$ (Average values followed by different letters in the same column are different by Tukey test $(P<.05)$ - coefficient of variation $=6.70 \%$ ).

a,b,c. Médias seguidas de letras diferentes na mesma coluna diferem entre si pelo teste de tukey $(P<0,05)$.

${ }^{1} \mathrm{MN}=$ na matéria natural $(\mathrm{MN}=$ as fed basis $)$.

${ }^{2}$ NRC (1994), Rostagno et al. (2000), D'Agostini et al. (2001) e Harmon et al. (2001). 
dietas com farelo de soja (TES), GM e OP resultaram em conversão alimentar intermediária.

Menores conversão alimentar e ganho de peso de aves alimentadas com $20 \%$ de ovo em pó na fase préinicial foram observados por Junqueira et al. (2001). Segundo esses autores, essa resposta se deve à presença de uma glicoproteína (avidina) presente na clara do ovo, a qual se complexa com a biotina, impedindo sua absorção, prejudicando, dessa forma, o metabolismo de carboidratos, gorduras e proteínas, uma vez que a biotina está envolvida nessas reações metabólicas.

Considerando que as dietas experimentais foram isonutritivas, mas formuladas para atender as exigências das aves em proteína bruta, pode-se relacionar a diferença na conversão alimentar com a digestibilidade da proteína (dados não avaliados), uma vez que se espera maior digestibilidade da proteína de ingredientes como o plasma sangüíneo e o isolado protéico de soja. Batal \& Parsons (2003) destacaram maior digestibilidade da proteína do isolado protéico de soja, embora tenham verificado pior desempenho das aves alimentadas com esse ingrediente em relação ao farelo de soja, o que atribuíram a um desbalanço de aminoácidos da dieta fornecida.

Ao serem alojadas, as aves dos diferentes tratamentos apresentaram uniformidade semelhante (entre 8,3 e 9,7\% de coeficiente de variação); e aos 7 dias de idade não se verificou efeito significativo $(\mathrm{P}>0,05)$ das diferentes fontes protéicas sobre essa variável.
A absorção do saco vitelino apresentou diferença significativa $(\mathrm{P}<0,10) 24$ horas após o fornecimento das dietas, sendo que os tratamentos com GM e OP prejudicaram, enquanto o PS estimulou a absorção do mesmo (Tabela 6). O fato de o OP ter prejudicado a absorção do saco vitelino nessas primeiras 24 horas pode ser reflexo da presença de nutrientes semelhantes em ambos, ao passo que a maior absorção apresentada pelas aves do tratamento com PS pode estar relacionada ao baixo consumo de ração nesse primeiro dia de vida da ave (dados não apresentados), fazendo com que as aves absorvessem o conteúdo do saco vitelino em busca de nutrientes. Aos 4 e 7 dias, não se verificou efeito significativo $(\mathrm{P}>0,10)$ dos tratamentos sobre o órgão.

De maneira geral, o saco vitelino foi absorvido rapidamente já no primeiro dia de vida, uma vez que as aves foram alojadas com cerca de $13,7 \%$ do peso vivo (PV) em saco vitelino, correspondendo a aproximadamente $6,5 \mathrm{~g}$. Com 24 horas de idade, as aves continham somente cerca de $3,6 \mathrm{~g}$ (6,2\% do PV) de saco vitelino residual, o que foi praticamente absorvido até o quarto dia (cerca de $0,75 \mathrm{~g}$ ); a absorção do saco vitelino de 4 a 7 dias foi praticamente completa, cerca de $0,5 \mathrm{~g}$. Essa quantidade provavelmente não tem efeito nutricional, validando ainda mais os valores de EMAn determinados no Experimento 1 para frangos nessa fase de criação. Os resultados estão de acordo com Iji et al. (2001), que constataram que frangos no sétimo dia de idade apresentavam saco vitelino representando menos

Tabela 5 - Valores médios de ganho de peso (GP), consumo de ração (CR), conversão alimentar (CA), uniformidade (UNIF) e viabilidade criatória (VIAB) de frangos de corte de 1 a 7 dias de idade alimentados com diferentes fontes de proteína

Table 5 - Average values of weight gain (GP), feed intake (CR), feed conversion (CA), uniformity (UNIF) and viability (VIAB) of the broilers from 1 to 7 days fed different protein sources

\begin{tabular}{|c|c|c|c|c|c|c|}
\hline & $\begin{array}{c}\mathrm{GP} \\
\text { (g/ave) } \\
(\text { g/bird) }\end{array}$ & $\begin{array}{c}\mathrm{CR} \\
\text { (g/ave) } \\
(\mathrm{g} / \text { bird })\end{array}$ & $\begin{array}{l}\text { CA } \\
(\mathrm{g} / \mathrm{g}) \\
\end{array}$ & $\begin{array}{c}\mathrm{UNIF}^{1} \\
\text { Inicial (initial) } \\
(\%) \\
\end{array}$ & $\begin{array}{c}\text { UNIF }^{1} \\
7 \text { dias (7 days) } \\
(\%) \\
\end{array}$ & $\begin{array}{c}\text { VIAB } \\
1 \text { a } 7 \text { dias }(1 \text { to } 7 \text { days }) \\
(\%)\end{array}$ \\
\hline TES & 122,0 & $137,0^{\mathrm{ab}}$ & $1,12^{b}$ & 8,5 & 9,9 & 100 \\
\hline IS & 123,8 & $124,2^{\mathrm{c}}$ & $1,01^{\mathrm{a}}$ & 8,3 & 9,6 & 100 \\
\hline OP & 112,2 & $125,4^{b c}$ & $1,12^{b}$ & 8,4 & 13,2 & 98,2 \\
\hline PS & 122,5 & $128,0 \mathrm{bc}$ & $1,05^{\mathrm{a}}$ & 8,7 & 11,0 & 100 \\
\hline GM & 115,7 & $130,2^{b c}$ & $1,13^{b}$ & 9,6 & 13,0 & 100 \\
\hline $\mathrm{LS}$ & 119,7 & $144,2^{\mathrm{a}}$ & $1,21^{\mathrm{c}}$ & 8,7 & 11,5 & 100 \\
\hline $\mathrm{CV}(\%)$ & 5,27 & 4,03 & 2,44 & 18,49 & 22,86 & 1,46 \\
\hline
\end{tabular}

a, b, c. Médias seguidas de diferentes letras na coluna diferem entre si pelo teste Tukey $(P<0,05)(A v e r a g e$ values followed by different letters in the same column differ by Tuket test $[P<.05])$.

${ }^{1}$ Média do coeficiente de variação dos pesos individuais das aves de cada parcela nos diferentes tratamentos (Average value of coefficient of variation of individual live weight of birds of each pen in the different treatments).

$\mathrm{CV}(\%)=$ coeficiente de variação (coefficient of variation).

\section{R. Bras. Zootec., v.34, n.1, p.112-122, 2005}


de $1 \%$ do peso vivo da ave e que a rápida absorção do conteúdo é considerada como fundamental nos primeiros dias de vida.

O desenvolvimento do proventrículo acompanhou o aumento do peso corporal das aves no decorrer da primeira semana (Tabela 6), sendo que com um dia de idade as aves apresentaram um peso relativo médio de cerca de $1,09 \%$, atingindo um pico de $1,35 \%$ aos quatro dias e redução para $1,18 \%$ aos sete dias. Somente no sétimo dia de idade foi verificado efeito significativo $(\mathrm{P}<0,10)$ dos tratamentos sobre o desenvolvimento desse órgão, sendo que o PS promoveu maior desenvolvimento em relação ao IS. Como o proventrículo é responsável pela secreção de $\mathrm{HCl}$ e pepsinogênio, que iniciam a digestão protéica, esperar-se-ia variação no tamanho do órgão, em função da quantidade de proteína ingerida, mas a variação do tamanho desse órgão não parece estar relacionada ao maior consumo de ração.

A moela das aves é considerada o estômago mecânico e variações em seu tamanho podem representar mudanças nas características físicas das dietas fornecidas. Entretanto, somente aos quatro dias observam-se mudanças significativas $(\mathrm{P}<0,10)$, sendo que o tratamento testemunha promoveu maior peso relativo deste órgão das aves em relação ao tratamento com GM, diferenças que provavelmente são resultados de variação entre os pintos. De maneira geral, o desenvolvimento da moela apresentou uma característica diferente dos outros órgãos das aves nessa fase, uma vez que promove o maior peso relativo nos pintos no primeiro dia de vida $(5,56 \%)$, superior aos demais órgãos do TGI, e é o único que decresce em relação ao peso vivo da ave com o passar de 1 a 7 dias de idade.

Entre os órgãos anexos do TGI (Tabela 7), o pâncreas, que é responsável pela secreção de enzimas de grande importância para a digestão protéica, não sofreu influência significativa no seu desenvolvimento em função dos tratamentos durante a fase. Verificou-se, entretanto, que o tratamento com PS promoveu aumento significativo no fígado $(\mathrm{P}<0,10)$ em relação ao tratamento com LS aos 7 dias de idade. Estas diferenças não foram observadas no primeiro e quarto dias.

De maneira geral, o pâncreas e o fígado atingiram um pico de peso em relação ao peso vivo em torno de quatro dias de idade $(0,532$ e $5,694 \%$, respectivamente). Máxima taxa de desenvolvimento foi verificada entre 1 e 4 dias, sendo que esses órgãos aumentaram em peso em quase duas vezes em relação ao peso do pinto.

Considerando-se somente os tratamentos com inclusão de fontes de alta concentração de proteína (IS, OP, OS e GM), pode-se observar que os pesos relativos do pâncreas e fígado foram numericamente superiores aos do tratamento TES. Esse maior desenvolvimento inicial ressalta a importância da adaptação da ave ao alimento ingerido e possivelmente indica maior qualidade da proteína fornecida, uma vez que, provavelmente, a necessidade de enzimas e de maior atividade metabólica dos subprodutos da digestão protéica estimula o rápido desenvolvimento do pâncreas e fígado, respectivamente. Segundo Corless \& Sell (1999), o peso do pâncreas pode representar mudanças na capacidade digestiva da ave, em razão da alta correlação entre o peso do mesmo com a atividade das enzimas digestivas pancreáticas.

Tabela 6 - Peso relativo (\% do peso vivo) do saco vitelino, proventrículo e moela aos 1, 4 e 7 dias de idade para frangos alimentados com diferentes fontes de proteína na dieta pré-inicial

Table 6 - Relative weight (\% of live weight) of yolk sac, proventriculum and gizzard at 1, 4 and 7 days of age for broilers fed different protein sources in the diets

\begin{tabular}{|c|c|c|c|c|c|c|c|c|c|}
\hline & \multicolumn{3}{|c|}{$\begin{array}{c}\text { Saco vitelino } \\
\text { Yolk sac }\end{array}$} & \multicolumn{3}{|c|}{$\begin{array}{l}\text { Proventrículo } \\
\text { Proventriculum }\end{array}$} & \multicolumn{3}{|c|}{$\begin{array}{l}\text { Moela } \\
\text { Gizzard }\end{array}$} \\
\hline & 1 dia & 4 dias & 7 dias & 1 dia & 4 dias & 7 dias & 1 dia & 4 dias & 7 dias \\
\hline & 1 day & 4 days & 7 days & 1 day & 4 days & 7 days & 1 day & 4 days & 7 days \\
\hline TES & $6,28^{a b}$ & 0,80 & 0,21 & 1,13 & 1,35 & $1,27^{\mathrm{ab}}$ & 5,60 & $5,42^{a}$ & 4,83 \\
\hline IS & $5,63^{a b}$ & 0,57 & 0,15 & 1,08 & 1,27 & $1,03^{b}$ & 5,51 & $5,24^{\mathrm{ab}}$ & 4,92 \\
\hline OP & $7,66^{\mathrm{a}}$ & 0,73 & 0,18 & 1,01 & 1,37 & $1,10^{\mathrm{ab}}$ & 5,44 & $5,00^{a b}$ & 4,39 \\
\hline PS & $4,11^{b}$ & 0,88 & 0,19 & 1,05 & 1,36 & $1,28^{\mathrm{a}}$ & 5,76 & $5,14^{a b}$ & 4,54 \\
\hline GM & $7,77^{\mathrm{a}}$ & 0,94 & 0,14 & 1,13 & 1,34 & $1,24^{\mathrm{ab}}$ & 5,40 & $4,87^{b}$ & 4,76 \\
\hline LS & $5,52^{a b}$ & 0,58 & 0,19 & 1,15 & 1,38 & $1,17^{a b}$ & 5,65 & $5,17^{a b}$ & 4,48 \\
\hline $\mathrm{CV}(\%)$ & 28,69 & 53,22 & 39,93 & 11,94 & 8,79 & 10,02 & 6,81 & 4,78 & 5,96 \\
\hline
\end{tabular}

a, b, c. Médias seguidas de diferentes letras na coluna diferem entre si pelo teste Tukey $(\mathrm{P}<0,10)$ (Average values followed by different letters in the same column differ by Tukey test $[P<.10])$.

R. Bras. Zootec., v.34, n.1, p.112-122, 2005 
As características de desenvolvimento do intestino delgado (ID) são apresentadas na Tabela 8. O peso relativo do ID vazio das aves alimentadas com PS foi significativamente menor $(\mathrm{P}<0,10)$ que das aves recebendo o tratamento com LS nas primeiras 24 horas. A adição de IS também reduziu o peso relativo do ID, entretantom o peso não diferiu significativamente dos demais $(P>0,10)$. Aos 4 dias, apesar de efeitos não-significativos, os tratamentos com fontes de alta concentração de proteína prejudicaram o desenvolvimento em peso do ID, sendo que aos 7 dias de idade essa observação se torna significativa $(\mathrm{P}<0,10)$, quando se considerou o tratamento PS em relação ao TES.

O desenvolvimento em tamanho do ID das aves não diferiu em relação aos tratamentos nas três idades avaliadas. Considerando o peso bruto por unidade de comprimento do ID, verifica-se que, após 24 horas de alimentação, os tratamentos com inclusão do IS e PS prejudicaram significativamente a densidade do ID em relação ao tratamento com LS. Aos 4 dias, não se observam diferenças significativas entre os tratamentos, enquanto aos 7 dias as aves do tratamento com GM apresentaram menor $(\mathrm{P}>0,10)$ densidade do ID que as dos tratamentos TES e IS.

Tabela 7- Peso relativo (\% do peso vivo) do pâncreas e fígado aos 1, 4 e 7 dias de idade para frangos alimentados com diferentes fontes de proteína na dieta pré-inicial

Table 7 - Relative weight (\% of live weight) of pancreas and liver at 1, 4 and 7 days of age for broilers fed different protein sources in the diets

\begin{tabular}{|c|c|c|c|c|c|c|}
\hline & \multicolumn{3}{|c|}{ Pâncreas (pancreas) } & \multicolumn{3}{|c|}{ Fígado (liver) } \\
\hline & 1 dia & 4 dias & 7 dias & 1 dia & 4 dias & 7 dias \\
\hline & 1 day & 4 days & 7 days & 1 day & 4 days & 7 days \\
\hline TES & 0,28 & 0,49 & 0,46 & 3,53 & 5,36 & $4,68^{\mathrm{ab}}$ \\
\hline IS & 0,25 & 0,52 & 0,54 & 3,72 & 5,63 & $5,16^{\mathrm{ab}}$ \\
\hline OP & 0,29 & 0,56 & 0,55 & 3,55 & 6,16 & $4,78^{a b}$ \\
\hline PS & 0,28 & 0,52 & 0,51 & 3,57 & 6,01 & $5,43^{\mathrm{a}}$ \\
\hline GM & 0,29 & 0,56 & 0,54 & 3,57 & 5,72 & $5,35^{a b}$ \\
\hline LS & 0,34 & 0,54 & 0,54 & 3,76 & 5,29 & $4,44^{b}$ \\
\hline $\mathrm{CV}(\%)$ & 24,63 & 11,72 & 12,82 & 10,64 & 9,09 & 9,85 \\
\hline
\end{tabular}

a, b. Médias seguidas de diferentes letras na coluna diferem entre si pelo teste Tukey $(P<0,10)$ (Average values followed by different letters in the same column differ by Tukey test $[P<.10])$.
Observando-se o desenvolvimento geral do ID nos diferentes tratamentos, verifica-se alta taxa de crescimento em peso relativo (de $2,44 \%$ a $4,14 \%$ ) e densidade $(27 \mathrm{mg} / \mathrm{cm}$ a $54 \mathrm{mg} / \mathrm{cm})$ entre 1 e 4 dias de idade, a partir dessa fase, parece ocorrer desenvolvimento acompanhado de crescimento total da ave. O comprimento do ID das aves dobrou de $1(50 \mathrm{~cm})$ a $7(98 \mathrm{~cm})$ dias de idade.

Considerando a relação peso:comprimento do ID, pode-se avaliar indiretamente o crescimento da mucosa intestinal, em que menores ou maiores densidades do intestino podem representar decréscimo ou aumento na altura e diâmetro das vilosidades, os quais promovem redução ou melhora na capacidade digestiva e absortiva do TGI (Uni et al., 1998). Segundo Uni et al (2000), o tamanho das criptas aumenta consideravelmente a partir da eclosão, atingindo um platô em aproximadamente 120 horas. A taxa de aumento do número de células por cripta também é maior nessa fase, atingindo valor máximo cerca de 108 horas pós-eclosão, declinando em seguida.

Não foram observadas diferenças significativas $(\mathrm{P}>0,05)$ para desempenho e viabilidade criatória das aves no período de 8 a 21 dias de idade (Tabela 9), demonstrando que os efeitos apresentados para desempenho e desenvolvimento dos órgãos do TGI, promovidos pelas diferenças na qualidade da proteína adicionada à dieta pré-inicial, não se mantiveram nessa fase subseqüente. Durante o desenvolvimento do experimento, verificou-se que a substituição da dieta pré-inicial, em que estavam presentes as diferentes fontes de proteína, pela dieta inicial à base de milho e farelo de soja foi prejudicial para o desenvolvimento das aves dos tratamentos com as fontes alternativas. Os resultados indicam a necessidade de adaptação das aves à nova composição da dieta ou ausência de alguns ingredientes, problemas que talvez poderiam ser minimizados com o fornecimento de uma dieta de adaptação em um período subseqüente.

Salienta-se a importância de maiores estudos sobre alguns dos ingredientes avaliados, a fim de se verificar o efeito de outras propriedades, além das nutricionais, de grande importância na fase inicial de vida sobre o desempenho de aves submetidas ao estresse de produção em piso. 
Tabela 8 - Peso relativo (\% do peso vivo), comprimento $(\mathrm{cm})$ e densidade $(\mathrm{mg} / \mathrm{cm})$ do intestino delgado aos 1,4 e 7 dias de idade para frangos alimentados com diferentes fontes de proteína na dieta pré-inicial

Table 8 - Relative weight (\% of live weight), length $(\mathrm{cm})$ and density $(\mathrm{mg} / \mathrm{cm})$ of small intestine at 1,4 and 7 days of age for broilers fed different protein sources in the diets

\begin{tabular}{|c|c|c|c|c|c|c|c|c|c|}
\hline & \multicolumn{3}{|c|}{$\begin{array}{l}\text { Peso relativo }(\% \mathrm{PV}) \\
\text { Relative weight }(\% L W)\end{array}$} & \multicolumn{3}{|c|}{$\begin{array}{c}\text { Comprimento }(\mathrm{cm}) \\
\text { Length }\end{array}$} & \multicolumn{3}{|c|}{$\begin{array}{c}\text { Densidade }(\mathrm{mg} / \mathrm{cm}) \\
\text { Density }\end{array}$} \\
\hline & $\begin{array}{l}1 \text { dia } \\
1 \text { day }\end{array}$ & $\begin{array}{l}4 \text { dias } \\
4 \text { days }\end{array}$ & $\begin{array}{l}7 \text { dias } \\
7 \text { days }\end{array}$ & $\begin{array}{l}1 \mathrm{dia} \\
1 \text { day }\end{array}$ & $\begin{array}{l}4 \text { dias } \\
4 \text { days }\end{array}$ & $\begin{array}{l}7 \text { dias } \\
7 \text { days }\end{array}$ & $\begin{array}{l}1 \text { dia } \\
1 \text { day }\end{array}$ & $\begin{array}{l}4 \text { dias } \\
4 \text { days }\end{array}$ & $\begin{array}{l}7 \text { dias } \\
7 \text { days }\end{array}$ \\
\hline$\overline{T E S}$ & $2,58 \mathrm{ab}$ & 4,44 & $4,47 \mathrm{a}$ & 50,00 & 81,38 & 103,13 & $29,00 \mathrm{ab}$ & 54,00 & $72,50 \mathrm{a}$ \\
\hline IS & $2,16 a b$ & 3,86 & $4,14 \mathrm{ab}$ & 50,63 & 75,63 & 94,63 & $23,00 \mathrm{~b}$ & 51,50 & $74,25 \mathrm{a}$ \\
\hline OP & $2,49 \mathrm{ab}$ & 3,72 & $3,54 \mathrm{ab}$ & 50,63 & 80,75 & 98,88 & $26,25 \mathrm{ab}$ & 50,00 & $58,50 \mathrm{ab}$ \\
\hline PS & $2,11 b$ & 3,88 & $3,41 \mathrm{~b}$ & 47,38 & 79,13 & 95,75 & $23,25 \mathrm{~b}$ & 52,75 & $62,00 \mathrm{ab}$ \\
\hline GM & $2,50 \mathrm{ab}$ & 4,12 & $3,62 \mathrm{ab}$ & 53,63 & 81,25 & 96,25 & $26,75 \mathrm{ab}$ & 53,75 & $56,00 \mathrm{~b}$ \\
\hline LS & $2,81 \mathrm{a}$ & 4,84 & $3,72 \mathrm{ab}$ & 48,63 & 78,75 & 98,75 & $32,50 \mathrm{a}$ & 62,00 & $60,50 \mathrm{ab}$ \\
\hline $\mathrm{CV}(\%)$ & 13,50 & 15,48 & 12,45 & 9,07 & 4,74 & 7,60 & 11,97 & 16,45 & 12,94 \\
\hline
\end{tabular}

a, b. Médias seguidas de diferentes letras na coluna diferem entre si pelo teste Tukey $(P<0,10)$ (Average values followed by different letters in the same column differ by Tukey test $[P<0.10])$.

Tabela 9 - Valores médios de ganho de peso (GP), consumo de ração (CR), conversão alimentar (CA), uniformidade (UNIF) e viabilidade criatória (VIAB) de frangos de corte de 8 a 21 dias de idade alimentados com diferentes fontes de proteína na fase pré-inicial

Table 9 - Average values of weight gain (GP), feed intake (CR), feed conversion (CA), uniformity (UNIF) and viability (VIAB) for broilers from 8 to 21 days fed different protein sources

\begin{tabular}{|c|c|c|c|c|c|}
\hline & $\begin{array}{c}\text { GP } \\
\text { (g/ave) } \\
\text { (g/bird) }\end{array}$ & $\begin{array}{c}\mathrm{CR} \\
\text { (g/ave) } \\
\text { (g/bird) }\end{array}$ & $\begin{array}{l}\mathrm{CA} \\
(\mathrm{g} / \mathrm{g})\end{array}$ & $\begin{array}{c}\text { UNIF }^{1} \\
21 \text { dias (21 days) } \\
(\%)\end{array}$ & $\begin{array}{c}\text { VIAB } \\
8 \text { a } 21 \text { dias( } 8 \text { to } 21 \text { days }) \\
(\%)\end{array}$ \\
\hline TES & 646,1 & 914,0 & 1,42 & 9,1 & 97,9 \\
\hline IS & 636,3 & 915,7 & 1,44 & 10,7 & 100 \\
\hline $\mathrm{OP}$ & 605,4 & 877,0 & 1,45 & 11,8 & 100 \\
\hline PS & 636,1 & 909,8 & 1,43 & 13,0 & 100 \\
\hline GM & 658,3 & 924,8 & 1,41 & 10,0 & 100 \\
\hline LS & 628,9 & 921,6 & 1,47 & 14,5 & 97,9 \\
\hline $\mathrm{CV}(\%)$ & 4,28 & 3,07 & 2,68 & 30,32 & 2,42 \\
\hline
\end{tabular}

a, b, c. Médias seguidas de diferentes letras na coluna diferem entre si pelo teste Tukey $(\mathrm{P}<0,05)$ (Average values followed by different letters in the same column differ by Tukey test $(P<0.05))$.

${ }_{1}^{1}$ Média do coeficiente de variação dos pesos individuais das aves de cada parcela dos diferentes tratamentos (Average value of coefficient of variation of individual live weight of birds of each pen of different treatments).

$\mathrm{CV}(\%)=$ coeficiente de variação (coefficient of variation).

\section{Conclusões}

A EMAn dos ingredientes avaliados no ensaio foi de $2.110,5.095,3.831,3.374$ e $2.037 \mathrm{kcal} / \mathrm{kg}$ (na matéria natural) para IS, OP, PS, GM e LS, respectivamente.

O desempenho das aves na fase pré-inicial foi afetado pelo tipo de fonte protéica fornecida, porém, o desenvolvimento do TGI parece estar relacionado mais com o consumo de ração do que com a qualidade da proteína adicionada na dieta durante a fase préinicial. Os efeitos promovidos pela qualidade da proteína durante a fase pré-inicial não se mantiveram no período subseqüente de criação.

\section{Agradecimento}

À Fundação de Amparo a Pesquisa do Estado de São Paulo (FAPESP), pelo suporte financeiro.

\section{Literatura Citada}

BATAL, A.B.; PARSONS, C.M. Utilization of different soy products as affected by age in chicks. Poultry Science, v. 82, p. 454-462, 2003.

BUTOLO, J.E. Qualidade de ingredientes na alimentação animal. 1.ed. Campinas: Colégio Brasileiro de Nutrição Animal, 2002. 430p.

CAMPBELL, J.; BORG, B.S.; WEAVER, E.M. Use of plasma protein in swine feeds examined. Feedstuffs, v.70, n.44, 1998, 3p. 
CORLESS, A.B.; SELL, J.L. The effects of delayed acess to feed and water on the physical and functional development of the digestive system of young turkeys. Poultry Science, v.78, p.1158-1169, 1999.

CORRING, T. The adaptation of digestive enzymes to the diet: Its physiological significance. Reproduction Nutrition Development, v.20, p.1217-1235, 1980.

D' AGOSTINI, P.; GOMES, P.C.; ALBINO, L.F.T. et al. Valores de composição química e energética de alguns alimentos para aves. In: REUNIÃO ANUAL DA SOCIEDADE BRASILEIRA DE ZOOTECNIA, 38., 2001, Piracicaba. Anais... Piracicaba: Fundação de Estudos Agrários Luiz de Queiroz, 2001. p.796-798.

DIBNER, J. Nutritional requirements of young poultry. In: ARKANSAS NUTRITON CONFERENCE, 1996, Fayetteville. Proceedings... Fayetteville: ARKANSAS POULTRY FEDERATION, 1996. p.15-27.

DUDLEY-CASH, W. Novel ways to improve broiler growth performance reviewed. In: AUSTRALIAN POULTRY SCIENCE SYMPOSIUM, 2002, Australia. Proceedings...Australia: AUSTRALIAN POULTRY ASSOCIATION, 2002. p.35.

FIGUEIREDO, A.N. O ovo em pó na alimentação de leitões recém-desmamados. Piracicaba: Escola Superior de Agricultura Luiz de Queiroz, 2002. 61p. Dissertação (Mestrado em Agronomia) - Escola Superior de Agricultura Luiz de Queiroz, 2002.

GOLDFLUS, F. Ingredientes derivados do processamento da soja aplicados na nutrição animal. In: SIMPÓSIO SOBRE MANEJO E NUTRIÇÃO DE AVES E SUÍNOS E TECNOLOGIA DA PRODUÇÃO DE RAÇÕES, 2001, Campinas. Anais... Campinas: Colégio Brasileiro de Nutrição Animal, 2001. p.97-188.

HARMON, B.G.; LATOUR, M.A.; NORBERG, S. The use of spray dried eggs as an ingredient in diets for infantile pigs and broilers. http://www.ansc.purdue.edu/swine/ swineday/sday01/sday01/10.pdf (13 dez. 2001).

IJI, P.A.; SAKI, A.; TIVEY, D.R. Body and intestinal growth of broiler chicks on a commercial starter diet. 1. Intestinal weight and mucosal development. British Poultry Science, v.42, p.505-513, 2001.

JIN, S.H.; CORLESS, A.; SELL, J.L. Digestive system development in post-hatch poultry. World's Poultry Science Journal, v.54, p.335-345, 1998.

JUNQUEIRA, O.M.; ARAÚJO, L.F.; ARAÚJO, C.S.S. et al. Desempenho de frangos de corte alimentados com ovo em pó. Revista Brasileira de Ciência Avícola, v.3, n.1, p.65-73, 2001.

MAIORKA, A. Adaptações digestivas pós-eclosão. In: CONFERÊNCIA APINCO DE CIÊNCIA E TECNOLOGIA AVÍCOLA - SIMPÓSIO INTERNACIONAL SOBRE MANEJO PRÉ E PÓS-ECLOSÃO, 2001, Campinas. Anais... Campinas: Fundação Apinco de Ciência e Tecnologia Avícola, 2001. p.141-152.
MATTERSON, L.D.; POTTER, L.M.; STUTZ, N.W. et al. The metabolizable energy of feed ingredients for chickens. Research Report, v.7, p.3-11, 1965.

MENTEN, J.F.M.; LONGO F.A.; PEDROSO, A.A. et al. Valores de energia metabolizável de milho e farelo de soja para frangos de corte na fase pré-inicial. In: REUNIÃO ANUAL DA SOCIEDADE BRASILEIRA DE ZOOTECNIA, 39., 2002, Recife. Anais... Recife: SBZ, 2002. CD-ROM. Nutrição de Não-Ruminantes

NIR, I. Mecanismos de digestão e absorção de nutrientes durante a primeira semana. In: CONFERÊNCIA APINCO DE CIÊNCIA E TECNOLOGIA A VÍCOLA, 1998, Campinas. Anais... Campinas: Fundação Apinco de Ciência e Tecnologia Avícola, 1998. p.81-91.

NATIONAL RESEARCH COUNCIL - NRC. Nutrients requirements of poultry. Washington D.C.: National Academiy Press, 1994. 155p.

PARSONS, C.M.; ZHANG, Y.; ARABA, M. Nutritional evaluation of soybean meals varying in oligosaccharide content. Poultry Science, v.79, p.1127-1131, 2000.

ROSTAGNO, H.S.; ALBINO, L.F.T.; DONZELE, J.L. et al. Tabelas brasileiras para aves e suínos: composição de alimentos e exigências nutricionais. Viçosa, MG: Universidade Federal de Viçosa, 2000. 141p.

STATISTICAL ANALYSES SYSTEM - SAS. SAS user's guide. Version 6.11. Cary: 1996. 956p.

SHELTON, J.L.; MAVROMICHALIS, I.; PAYNE, R.L. et al. Growth performance of different breed crosses of chicks fed diets with different protein and energy sources. Poultry Science, v.82, p.272-278, 2003.

SILVA, D.J. Análise de alimentos (Métodos químicos e biológicos). 2.ed. Viçosa, MG: Universidade Federal de Viçosa, 1990. 165p.

UNI, Z.; GEYRA, A.; BEN-HUR, H. et al. Small intestinal development in the young chick:crypt formation and enterocyte proliferation and migration. British Poultry Science, v.41, p.544-551, 2000.

UNI, Z.; GANOT, S.; SKLAN, D. Post-hatch development of mucosal function in the broiler small intestine. Poultry Science, v.77, p.75-82, 1998.

UNI, Z.; NOY, Y.; SKLAN, D. Post-hatch changes in morphology and function of the small intestine in heavy and light strain chicks. Poultry Science, v.74, p.1622-1629, 1995.

Recebido em: 04/11/03 Aceito em: 17/09/04 